\title{
Initial Training Programs' Development in Physical Education through Video Viewing Courses of Exemplary Teaching Exercises
}

\author{
Ghazi Rekik ${ }^{1,2}$, Naila Bali1,3 \\ ${ }^{1}$ High Institute of Sport and Physical Education, Ksar-Saïd, University of Manouba, UMA, Tunis, Tunisia \\ ${ }^{2}$ Tunisian Research Unit: Education, Motricity, Sport and Health, UR15JS01, High Institute of Sport and Physical Education of \\ Sfax, University of Sfax, Sfax, Tunisia \\ ${ }^{3}$ Tunisian Research Laboratory Sport Performance Optimization, Tunis, Tunisia \\ Email: rekikgahzi61@yahoo.fr
}

How to cite this paper: Rekik, G., \& Bali, N. (2017). Initial Training Programs' Development in Physical Education through Video Viewing Courses of Exemplary Teaching Exercises. Creative Education, 8, 2199-2209. https://doi.org/10.4236/ce.2017.814150

Received: October 5, 2017

Accepted: November 6, 2017

Published: November 9, 2017

Copyright $\odot 2017$ by authors and Scientific Research Publishing Inc. This work is licensed under the Creative Commons Attribution International License (CC BY 4.0).

http://creativecommons.org/licenses/by/4.0/

\begin{abstract}
The present study examined the effect of integrating video viewing courses of exemplary teaching exercises during the start-up of the academic year of teaching practice on the Pre-service Teachers' perceptions towards the initial training programs' effectiveness in physical education. Two hundred thirty two Pre-service Teachers (92 females and 140 males) aged between 21 and 23 $\left(\mathrm{M}_{\text {age } \leq S \mathrm{D}}=21 \pm 1.8\right.$ years $)$ were recruited. Participants were randomly allocated into a control group (46 females, 70 males) which received a Traditional Form of Initial Training Program (TF-ITP), and an experimental group (46 females, 70 males) which received the New Form of Initial Training Program (NF-ITP). Responses to the Q4TE questionnaire (Grohmann \& Kauffeld, 2013) for the assessment of the initial training programs' effectiveness were obtained in the completion period of the initial training. The Pre-service Teachers' perceptions regarding the initial training programs' effectiveness were significantly higher during the NF-ITP in comparison with the TF-ITP $(p<0.001)$ without any difference between genders. Findings suggested that integrating video viewing courses of exemplary teaching exercises during the start-up of the academic year of teaching practice would lead to make the initial training programs more efficient for the Pre-service Teachers of physical education.
\end{abstract}

\section{Keywords}

Video Viewing, Exemplary Teaching Exercises, Teacher Education, Physical Education 


\section{Introduction}

During the last decade, a sharp number of studies have examined the influence of video viewing on teacher education (Gaudin \& Chaliès, 2015). Therefore, the literature reveals two different instructional approaches to video viewing in teacher education. The first one is designed from a developmental approach and its aim is to help Pre-service Teachers (P-sT) to elaborate action means by interpreting and reflecting on classroom practices (Sherin, 2004). The second one is designed from a normative approach and its aim is to make P-sT observe and learn what to do in the classroom (Brouwer, 2011). For example, by showing examples of good teaching practices (Marsh, Mitchell \& Adamczyk, 2010; Seago, 2003) or typical classroom lessons (Clarke et al., 2008; Yung, Wong, Cheng, Lam, \& Hodson, 2007), and guide/coach teaching (Fadde \& Rich, 2010; Janík \& al., 2009; Masats, Sormunen, Hacklin, \& Ducos, 2007).

According to the two different instructional approaches to video viewing in teacher education, most studies underline many benefits of video viewing. Among the most significant benefits is heightened motivation, improved teaching activity, and optimized selective attention and knowledge-based reasoning (Gaudin \& Chaliès, 2015). Concerning video viewing and pre-service teachers' motivation, studies showed the influence of video on teacher motivation (Barnett \& Tyson, 1999; Moreno \& Valdez, 2007). As Sherin (2004) pointed out, video tends to be similar to authentic experience in that it positively affects intrinsic motivation and interest. For instance, pre-service teachers' level of satisfaction was found to be higher when teacher education courses use video rather than textual support or narrations of experience (Choi \& Johnson, 2007; Moreno, Abercrombie, \& Hushman, 2009). Paradoxically, little empirical evidence has been presented on the benefits of video use on actual classroom practice (Seidel, Stürmer, Blomberg, Kobarg, \& Schwindt, 2011). However, studies showed that the main effect of video use is to improve P-sT wittiness (Snoeyink, 2010) and prepare them emotionally and intellectually for the classroom (Koc, 2011; Wang, 2013). For example, Karsenti and Collin (2011) documented the impact of online teaching videos on the development of self-efficacy beliefs in P-sT. Generally, video use has been found to inspire habits of praxis (Hewitt, Pedretti, Bencze, Vaillancourt, \& Yoon, 2003) in three broad areas: planning and preparation for differentiation, classroom management Overbaugh (1995), and teaching and learning (Harford, MacRuairc, \& McCartan, 2010). In the other hand, numerous studies showed that using video enriches the ability to interpret observed events; it promotes the shift from partial, more or less detailed, descriptive analyses to more focused, specific, and interpretative analyses (Rosaen, Lundeberg, Cooper, Fritzen, \& Terpstra, 2008; Star \& Strickland, 2008). For example, Santagata and Guarino (2011) showed that, in training programs that use video, P-sT learnt to better interpret the reasons for and consequences of the decisions made by the videoed teacher. Other studies reported that video use enhances selective attention. By the video use, teacher educators can develop strategies to focus their 
attention on the most relevant classroom events (Brunvand, 2010). P-sT develop and increase their ability to identify relevant events because, as they watch the video, they are not only able to focus on the teachers' activity, but also on the students' as well (Sherin \& van Es, 2005; Yerrick, Ross \& Molebash, 2005). Furthermore, Scott, Kucan, Correnti, \& Miller (2013); Yadav \& Koehler, (2007) showed that video viewing challenges P-sT assumptions and helps them to critically examine their beliefs and values about teaching and learning. Studies also showed the effectiveness of video self-analysis in helping P-sT to identify relevant classroom interactions and, more specifically, to take students' perspective and to become better able to identify how well they have understood (Snoeyink, 2010). In view of the above consideration, it seems that video has become a permanent element in teacher training (Sherin, 2004).

In Tunisia, High Institutes of Sports and Physical Education provide for future physical education teachers an initial training program includes two academic years based on human/biological sciences and physical activities, and a third academic year of teaching practice where the scientific and pedagogical subjects are distributed throughout the course (Rekik \& Bali, 2017). During this last year, P-sT are integrated in a school and assume all the responsibilities of a regular teacher (Beck \& Kosnik, 2000). Thus, among the twelve professional competences of teacher (MEQ, 2001), P-sT are asked during their internship to design teaching/learning situations for the contents to be learned, according to the pupils concerned and the development of the skills referred to in the training program. That is why it is necessary to push towards an improvement of our initial training program, particularly during the third academic year of teaching practice in order to develop this sort of competence as well in order to prepare well the future teachers to a successful professional life. To the best of our knowledge, no empirical evidence is available about the effect of integrating video viewing courses of exemplary teaching exercises on the Pre-service Teachers' perceptions towards the initial training programs' effectiveness in physical education. In this exploratory study, it was hypothesized that integrating this sort of courses during the start-up of the academic year of teaching practice would lead to make the initial training programs more efficient for the Pre-service Teachers.

\section{Material \& Methods}

\subsection{Participants}

An opportunity sample of two hundred and thirty two Pre-service Teachers (92 females and 140 males) aged between 21 and $23\left(\mathrm{M}_{\text {age } \pm \mathrm{SD}}=21 \pm 1.8\right.$ years $)$ was recruited from Tunisian High Institutes of Sports and Physical Education. All $\mathrm{P}-\mathrm{sT}$ are registered in the training program as part of the preparatory internship for the professional life during their final academic year of studies, in which they are supposed to obtain their fundamental license in physical education. Participants were randomly allocated into a control group (46 female, 70 male) and an experimental group ( 46 female, 70 male). These groups of P-sT to compare the 
effectiveness of two initial training programs' forms: Traditional Form vs. New Form. They were informed about the experimental procedures and they signed a written informed consent prior to participation. The experiment was conducted according to the Declaration of Helsinki and approval was obtained from the local Institutional Ethics Committee.

\subsection{Experimental Design and Dependant Measures}

Pre-service Teachers received two forms of initial training program: Participants of the control group received a Traditional Form of Initial Training Programs (TF-ITP $=$ two academic years of human/biological sciences, physical activities and a third academic year of teaching practice where the scientific and pedagogical subjects are distributed throughout the course). Participants of the experimental group received a New Form of Initial Training Programs (NF-ITP = TF-ITP + integrating video viewing courses of exemplary teaching exercises during the start-up of the academic year of teaching practice) (Figure 1).

The integration of these lessons was done in collaboration with 4 educators from two institutes of sports and physical education. Eight conferences were organized successively for the experimental group during eight days at the rate of one conference per day which lasts $1 \mathrm{~h} 30 \mathrm{~min}$. The experiment was conducted using a HP Pavilion Entertainment PC and the stimuli were presented on a 250 $\mathrm{cm} \times 200 \mathrm{~cm}$ screen from a video projection system. The image on the screen was $200 \mathrm{~cm} \times 160 \mathrm{~cm}$, with a $45^{\circ}$ viewing angle. In this phase, participants were asked to visualize the model clips of exemplary teaching exercises and to note and/or draw on a sheet of paper the (aim, schema, instructions and materiel used) of each exercise. The instructional content consisted of exemplary teaching exercises related to four types of physical and sports activities that must be taught during the preparatory internship for the professional life. Model clips were collected From YouTube, editing by Movavi Video Editor Software. In addition, three experienced college supervisors of physical education (mean age $=$

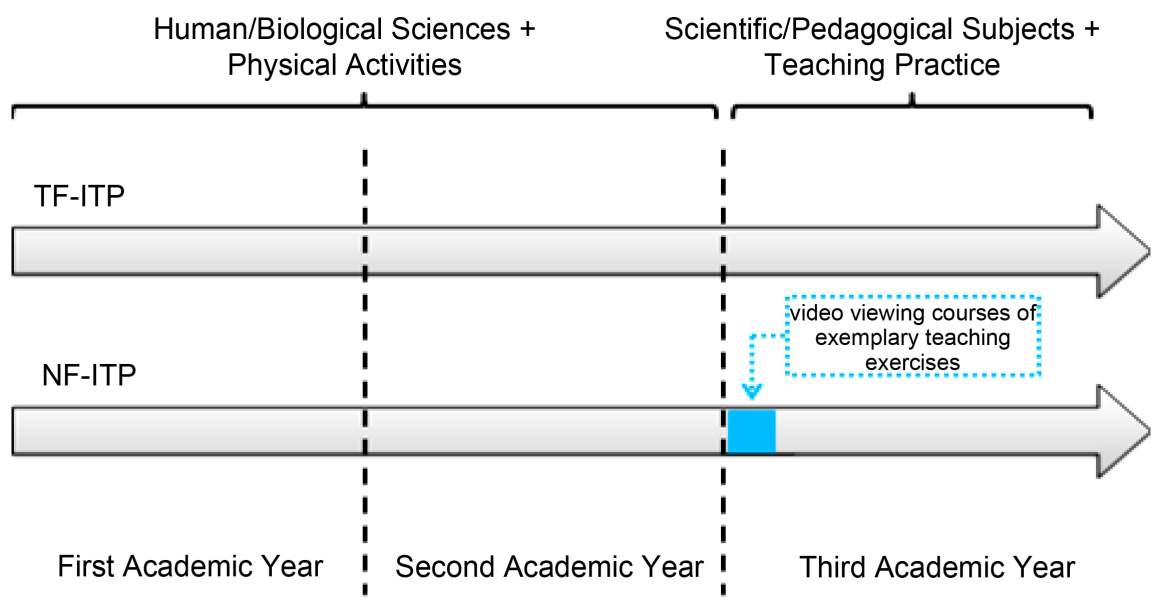

Figure 1. Schematic presentation of the two initial training programs' forms in physical education. 
46 years, mean experience $=12.5$ years) independently rated on a 5 -point Likert scale each sequence to guarantee that the illustrated information was a realistic depiction of an exemplary teaching exercises $(0=$ very non representative, $5=$ very representative). Nineteen sequences of exemplary teaching exercises were rated 4 or above and thus were kept for the experimentation (Table 1).

The (Q4TE; Grohmann \& Kauffeld, 2013) responses were taken in the completion period of the initial training. All participants of the experimental and control group were asked to assess the effectiveness of the initial training program on a 10-point rating scale (from totally disagree [0] to totally agree [10]) with six subscales (satisfaction, utility, knowledge, application to practice, the individual organizational results, and the global organizational results). Satisfaction refers to whether initial training programs were satisfactory. Utility refers to whether initial training programs were usefulness in teaching practice during the internship. Knowledge refers to whether initial training programs have contributed in the acquirement of new knowledge. Application to practice refers to whether content of initial training programs have been applied in teaching practice during the internship. The individual organizational results refer to whether initial training programs have contributed in the improvement of teaching practice performances during the internship. The global organizational results refer to whether initial training programs have contributed in the amelioration of teaching practice climate during the internship. In this test phase, the instruction given to the participants of experimental group is to indicate the number of

Table 1. Content of exemplary teaching exercises' videos.

\begin{tabular}{|c|c|}
\hline $\begin{array}{l}\text { Physical and sports } \\
\text { activities }\end{array}$ & Content of exemplary teaching exercises \\
\hline Basketball \& handball & $\begin{array}{l}\text { - Creative Moves Warm Up Drills. } \\
\text { - Warm up fun and games. } \\
\text { - Individual drills: Development of “jumping ability", Agility, } \\
\text { - Coordination, Ball control. } \\
\text { - } \text { Dribbling, passing and shooting drills. } \\
\text { - Attack and Defend Games in a small group. } \\
\text { - Small-Sided Transition Games Progressing to Goal in a small } \\
\text { group. }\end{array}$ \\
\hline Running & $\begin{array}{l}\text { - Dynamic and static Warm up: before running. } \\
\text { - } \text { Reaction Drills and Block Start Drills } \\
\text { - Basic Drills to Improve Running Form } \\
\text { - Developing Speed Drills } \\
\text { - Stretching: After running }\end{array}$ \\
\hline Long Jump & $\begin{array}{l}\text { - } \text { General and Specific Warm up } \\
\text { - Drills to improve running technique } \\
\text { - } \quad \text { Lrills to Increase Vertical Jump } \\
\text { - The take-off Drills } \\
\text { - The Hitch Kick Drills } \\
\text { - The flight Drills }\end{array}$ \\
\hline
\end{tabular}


conferences that they assisted. The exclusion criterion was to eliminate copies of each participant who assisted less than eight conferences.

\subsection{Statistical Analysis}

All statistical tests were processed using STATISTICA Software (Stat Soft, France, version 8.0 for Windows). After the verification of normality with the Shapiro-Wilk test, data were analyzed using a two factors ANOVA (2 [Forms] $\times$ 2 [Genders]) with repeated measures. When ANOVAs revealed a significant difference, post-hoc multiple comparisons using the LSD Fisher's test was conducted. Partial eta-squared $\left(n_{p}^{2}\right)$ were calculated to assess the practical significance of our results. The level of significance was set at $p<0.05$.

\section{Results}

The reliability coefficient obtained by Cronbach's alpha for the overall assessment of the initial training programs' effectiveness was 0.96 , and it was $0.68,0.9$, $0.82,0.88,0.89$, and 0.92 for, satisfaction, utility, knowledge, application to practice, the individual organizational results, and the global organizational results respectively.

The two-way ANOVA was conducted on overall responses score showed a significant main effect of forms $F=195.34, p<0.001, n_{p}^{2}=0.33$, non significant gender effect $F=1.39, p>0.05, n_{p}^{2}=0.03$, and non significant interaction (form x gender) $F=1.89, p>0.05, n_{p}^{2}=0.18$ ).

In each of the individual subscales-satisfaction, utility, knowledge, application to practice, the individual organizational results, and the global organizational results-analysis indicated that Pre-service Teachers' perceptions regarding the initial training programs' effectiveness were significantly higher during the NF-ITP in comparison with the TF-ITP $(p<0.001)$ without any difference between genders (Table 2).

Table 2. Mean of pre-service teachers' perceptions \pm (standard deviations), towards the effectiveness of the two initial training programs' forms.

\begin{tabular}{ccccc}
\hline \multirow{2}{*}{ Q4TE Subscales } & \multicolumn{2}{c}{ TF-ITP } & \multicolumn{2}{c}{ NF-ITP } \\
\cline { 2 - 5 } & Females & Males & Females & Males \\
\hline Satisfaction & $4.93(0.36)$ & $5.31(0.28)$ & $7.16^{\star}(0.18)$ & $6.88^{\star}(0.19)$ \\
Utility & $4.8(0.42)$ & $5.61(0.29)$ & $8.12^{\star}(0.19)$ & $7.41^{\star}(0.16)$ \\
knowledge & $4.8(0.39)$ & $5.87(0.27)$ & $7.7^{*}(0.19)$ & $7.81^{\star}(0.14)$ \\
Application to practice & $4.5(0.38)$ & $4.91(0.3)$ & $7.25^{\star}(0.18)$ & $7.43^{\star}(0.14)$ \\
Individual organizational results & $5(0.42)$ & $5.29(0.31)$ & $7.45^{\star}(0.22)$ & $7.62^{\star}(0.15)$ \\
Global organizational results & $4.6(0.38)$ & $5.11(0.33)$ & $7.13^{\star}(0.23)$ & $7.7^{\star}(0.16)$ \\
\hline
\end{tabular}

*Significant difference between NF-ITP and TF-ITP. 


\section{Discussion}

The study examined how an integration of video viewing courses of exemplary teaching exercises during the start-up of the academic year of teaching practice could enhance the Pre-service Teachers' perceptions towards initial training programs' effectiveness in physical education. To determine this dependent variable, a validated Questionnaire For Training Evaluation (Q4TE; Grohmann \& Kauffeld, 2013) was used. Results shows those P-sT who learned from the NF-ITP reported significantly higher assessment levels than P-sT who learned from the TF-ITP towards-satisfaction, utility, knowledge, application to practice, the individual organizational results, and the global organizational resultssubscales.

First, findings of the present study mentioned that P-sT becomes more satisfied when they received an initial training program containing video viewing courses of exemplary teaching exercises during the start-up of the academic year of teaching practice. The results are consistent with previous research carried out in the influence of video viewing on teacher education domain, demonstrating the influence of video on Pre-service Teachers' level of satisfaction. For example in a study carried out by Choi \& Johnson (2007), authors have tried to identify the effects of two major components (i.e., video and group discussion) of problem-based video instruction (PBVI) on college students' learning. To achieve this purpose, this study examined whether or not PBVI can improve learner satisfaction, comprehension and retention by comparing the results from three dependent variables in PBVI with two other kinds of instruction: 1) problem-based text instruction (PBTI) and 2) PBVI without group discussion. According to the findings, there were significant differences in learner satisfaction, comprehension, and delayed retention between PBVI and PBTI groups, whereas there were no significant differences in learners' satisfaction, comprehension, and delayed retention between PBVI and PBVI without group discussion. This study implies that PBVI in college courses have the potential to enhance student satisfaction, comprehension and delayed retention. Second, P-sT mentioned that initial training programs containing video viewing courses of exemplary teaching exercises during the start-up of the academic year of teaching practice supports them in the acquirement of new knowledge. Findings are in agreement with previous studies carried out in the benefits of video viewing on Pre-service Teachers' orientations, knowledge and skills for analyzing and reflecting on mathematics teaching in ways that generate knowledge for improvement (Santagata \& Guarino, 2011). Also, results are consistent with research carried out by Star \& Strickland (2008) who have demonstrated that video-supported reflection enabled interns to write more specific (vs. general) comments about their teaching than writing from memory, shift the content of the reflections from a focus on classroom management in memory-based reflections to a focus on instruction when video was available, and focus less on themselves and more on children 
when they reflected on video clips of their teaching. In addition, P-sT mentioned the practical application of the content of this sort of this new initial training programs' form in teaching practice during the internship. Finally, P-sT declared the improvement of their teaching practice performances and by the amelioration of their teaching practice climate, when they received an initial training program containing video viewing courses of exemplary teaching exercises during the start-up of the academic year of teaching practice. Likewise, results confirm studies carried out in the benefits of video viewing on Pre-service Teachers' classroom practice that demonstrated that online videos of teaching practices contribute positively to feelings of self-efficacy in Pre-service Teachers during their internship (Karsenti \& Collin, 2011; Fadde \& Sullivan, 2013). In this study, it means that the integration of video viewing courses of exemplary teaching exercises during the start-up of the academic year of teaching practice is a valuable device to enhance the initial training programs' effectiveness for Pre-service Teachers. Although the present study makes useful contribution in teacher education particularly in physical education domain, certain limitations should be kept in mind, when interpreting the results, as the choice of the content of exemplary teaching exercises' videos. In this study, we have based only on exemplary teaching exercises related to four types of physical and sports activities, while the P-sT are asked to teach six types of physical and sports activities during the preparatory internship for the professional life. Moreover, examination of findings of this study in more realistic circumstances is recommended. In sum, this study aimed at describing the benefit of using video viewing courses of exemplary teaching exercises in the initial training programs of physical education. The results recommend the integration of this sort of courses during the start-up of the academic year of teaching practice in order to make the initial training programs more efficient for the Pre-service Teachers.

\section{Conclusion}

The present study demonstrates that an integration of video viewing courses of exemplary teaching exercises during the start-up of the academic year of teaching practice may contribute to the development of the initial training programs' effectiveness in physical education. Thus, High Institutes of Sports and Physical Education could integrate video viewing courses of exemplary teaching exercises during the start-up of the academic year of teaching practice.

\section{Acknowledgements}

The authors wish to express their sincere gratitude to all the participants and educators from the Tunisian Institutes of Sport and Physical Education for their cooperation.

\section{Disclosure Statement}

No potential conflict of interest was reported by the authors. 


\section{Ethical Approval}

All procedures performed in study involving human participants were in accordance with the ethical standards of the institutional and/or national research committee and with the 1964 Helsinki declaration and its later amendments or comparable ethical standards. Informed consent was obtained from all individual participants included in the study.

\section{References}

Barnett, C. S., \& Tyson, P. A. (1999). Case methods and Teacher Change: Shifting Authority to Build Autonomy. In M. A. Lundeberg, B. B. Levin, \& H. L. Harrington (Eds.), Who Learns What from Cases and How? (pp. 53-69). Mahwah, NJ: Lawrence Earlbaum Associates.

Beck, C., \& Kosnik, C. (2000). Associate Teachers in Pre-Service Education: Clarifying and Enhancing Their Role. Journal of Education for Teaching: International Research and Pedagogy, 26, 207-224. https://doi.org/10.1080/713676888

Brouwer, C. N. (2011). Imaging Teacher Learning. A Literature Review on the Use of Digital Video for Pre-Service Teacher Education and Professional Development. In The Annual Meeting of the American Educational Research Association in New Orleans. Nijmegen: ILS Graduate School of Education, Radboud University Nijmegen.

Brunvand, S. (2010). Best Practices for Producing Video Content for Teacher Education. Contemporary Issues in Technology and Teacher Education, 10, 247-256.

Choi, H. J., \& Johnson, S. D. (2007). The Effect of Problem-Based Video Instruction on Learner Satisfaction, Comprehension and Retention in College Courses. British Journal of Educational Technology, 38, 885-895. https://doi.org/10.1111/j.1467-8535.2006.00676.x

Clarke, D. J., Mesiti, C., O’Keefe, C., Xu, L. H., Jablonka, E., Mok, I. A. C. et al. (2008). Addressing the Challenge of Legitimate International Comparisons of Classroom Practice. International Journal of Educational Research, 46, 280-293.

Fadde, P. J., \& Rich, P. (2010). Guerrilla Video: A New Protocol for Classroom Video. Educational Technology, 50, 4-8.

Fadde, P., \& Sullivan, P. (2013). Using Interactive Video to Develop Preservice Teachers' Classroom Awareness. Contemporary Issues in Technology and Teacher Education, 13, 156-174.

Gaudin, C., \& Chaliès, S. (2015). Video Viewing in Teacher Education and Professional Development: A Literature Review. Educational Research Review, 16, 41-67.

Grohmann, A., \& Kauffeld, S. (2013). Evaluating Training Programs: Development and Correlates of the Questionnaire for Professional Training Evaluation. International Journal of Training and Development, 17, 135-155. https://doi.org/10.1111/ijtd.12005

Harford, J., MacRuairc, G., \& McCartan, D. (2010). Lights, Camera, Reflection: Using Peer Video to Promote Reflective Dialogue among Student Teachers. Teacher Development, 14, 57-68. https://doi.org/10.1080/13664531003696592

Hewitt, J., Pedretti, E., Bencze, L., Vaillancourt, B. D., \& Yoon, S. (2003). New Applications for Multimedia Cases: Promoting Reflective Practice in Preservice Teacher Education. Journal of Technology \& Teacher Education, 11, 483-500.

Janík, T., Janíková, M., Knecht, P., Kubiatko, M., Najvar, P., Najvarová, V., \& Šebestová, S. (2009). Exploring Different Ways of using Video in Teacher Education: Examples from CPV Video Web. In T. Janík, \& T. Seidel (Eds.), The Power of Video Studies in 
Investigating Teaching and Learning in the Classroom (pp. 207-224). Munich: Waxmann Publishing.

Karsenti, T., \& Collin, S. (2011). The Impact of Online Teaching Videos on Canadian Pre-Service Teachers. Campus-Wide Information Systems, 28, 195-204. https://doi.org/10.1108/10650741111145724

Koc, M. (2011). Let's Make a Movie: Investigating Pre-Service Teachers' Reflections on using Video-Recorded Role Playing Cases in Turkey. Teaching and Teacher Education, 27, 95-106.

Marsh, B., Mitchell, N., \& Adamczyk, P. (2010). Interactive Video Technology: Enhancing Professional Learning in Initial Teacher Education. Computers \& Education, 54, 742-748.

Masats, D., Sormunen, K., Hacklin, S., \& Ducos, G. (2007). The Use of Online Video Case Studies in Teacher Training Programs: A Literature Review. Paper Presented at the 32nd ATEE Conference, Telford, 25-29 August 2007.

Ministry of Education of Quebec (MEQ) (2001). Training Program of the Quebec School. Pre-School Education. Primary Education. Quebec: Government of Quebec.

Moreno, R., \& Valdez, A. (2007). Immediate and Delayed Effects of using a Classroom Case Exemplar in Teacher Education: The Role of Presentation Format. Journal of Educational Psychology, 99, 194. https://doi.org/10.1037/0022-0663.99.1.194

Moreno, R., Abercrombie, S., \& Hushman, C. (2009). Using Virtual Classroom Cases as Thinking Tools in Teacher Education. In Proceedings of Society for Information Technology \& Teacher Education International Conference (pp. 2615-2622).

Overbaugh, R. C. (1995). The Effects of Course Focus on Pre-Service Teachers' Attitudes toward Personal and School Uses of Computers and Computer Anxiety. Journal of Computing in Teacher Education, 12, 18-23.

Rekik, G., \& Bali, N. (2017). Tunisian Physical Education Student Trainees' Agreement Rate about the Consistency between Initial Training and Integration during the Preparatory Internship for Professional Life. Creative Education, 8, 373-382.

https://doi.org/10.4236/ce.2017.83029

Rosaen, C. L., Lundeberg, M., Cooper, M., Fritzen, A., \& Terpstra, M. (2008). Noticing Noticing: How Does Investigation of Video Records Change How Teachers Reflect on Their Experiences? Journal of Teacher Education, 59, 347-360. https://doi.org/10.1177/0022487108322128

Santagata, R., \& Guarino, J. (2011). Using Video to Teach Future Teachers to Learn from Teaching. ZDM the International Journal of Mathematics Education, 43, 133-145. https://doi.org/10.1007/s11858-010-0292-3

Scott, S. E., Kucan, L., Correnti, R., \& Miller, L. A. (2013). Using Video Records to Mediate Teaching Interns' Critical Reflection. Journal of Technology and Teacher Education, 21, 119-145.

Seago, N. (2003). Using Video as an Object of Inquiry Mathematics Teaching and Learning. In J. Brophy (Ed.), Using Video in Teacher Education (Vol. 10, pp. 259-285). Amsterdam: Advances in Research on Teaching.

Seidel, T., Stürmer, K., Blomberg, G., Kobarg, M., \& Schwindt, K. (2011). Teacher Learning from Analysis of Videotaped Classroom Situations: Does It Make a Difference Whether Teachers Observe Their Own Teaching or That of Others? Teaching and Teacher Education, 27, 259-267.

Sherin, M. G. (2004). New Perspectives on the Role of Video in Teacher Education. In J. Brophy (Ed.), Using Video in Teacher Education (pp. 1-28). Amsterdam: Elsevier. 
Sherin, M. G., \& van Es, E. A. (2005). Using Video to Support Teachers' Ability to Notice Classroom Interactions. Journal of Technology and Teacher Education, 13, 475e491.

Snoeyink, R. (2010). Using Video Self-Analysis to Improve the "Withitness" of Student Teachers. Journal of Digital Learning in Teacher Education, 26, 101-110.

Star, J., \& Strickland, S. (2008). Learning to Observe: Using Video to Improve Pre-Service Mathematics Teachers' Ability to Notice. Journal of Mathematics Teacher Education, 11, 107-125. https://doi.org/10.1007/s10857-007-9063-7

Wang, X. (2013). A Potential Approach to Support Pre-Service Teachers' Professional Learning: The Video Analysis of the Authentic Classroom. US-China Education Review $B, 3,149-161$.

Yadav, A., \& Koehler, M. J. (2007). The Role of Epistemological Beliefs in Preservice Teachers' Interpretation of Video Cases of Early-Grade Literacy Instruction. Journal of Technology and Teacher Education, 15, 335-361.

Yerrick, R., Ross, D., \& Molebash, P. (2005). Too Close for Comfort: Real-Time Science Teaching Reflections via Digital Video Editing. Journal of Science Teacher Education, 16, 351-375. https://doi.org/10.1007/s10972-005-1105-3

Yung, B. H. W., Wong, S. L., Cheng, M. W., Hui, C. S., \& Hodson, D. (2007). Tracking Pre-Service Teachers' Changing Conceptions of Good Science Teaching: The Role of Progressive Reflection with the Same Video. Research in Science Education, 37, 239-259. https://doi.org/10.1007/s11165-006-9024-7 